\title{
Electrochemical Behavior of Vanadium in Azide Electrolyte in Comparison with the Behavior in Halogen Ions-Containing Electrolytes
}

\author{
A.A. Ghoneim*
}

Chemistry Department, Faculty of Science, Cairo University, Giza 12613, Egypt

\begin{abstract}
The influence of azide ion concentration and temperature on the electrochemical behavior of vanadium was studied using open-circuit potential (OCP), potentiodynamic polarization and electrochemical impedance spectroscopy (EIS) techniques. The steady state potential $\left(\mathrm{E}_{\mathrm{ss}}\right)$ is a linear function of azide ion concentration. Polarization measurements have shown that the rate of corrosion $i_{\text {corr }}$ increases with increasing the azide ion concentration as well as increasing solution temperature. EIS investigations under open-circuit conditions confirm these results as can be identified by the decrease of the polarization resistance $\left(\mathrm{R}_{\mathrm{ox}}\right)$ and oxide thickness $\left(1 / \mathrm{C}_{\mathrm{ox}}\right)$ with increasing the azide ion concentration. The measured impedance responses were analyzed using a constant phase element (CPE) model with its complex transfer function. The behavior of vanadium in the azide medium is also compared to that in other halide salt solutions, it was found that the tendency for spontaneously grown thicker oxide film increases in the order: $\mathrm{Br}^{-}>\mathrm{Cl}^{-}>\mathrm{I}^{-}>\mathrm{N}_{3}^{-}>\mathrm{F}^{-}$.
\end{abstract}

Keywords: Vanadium, corrosion, azide, polarization, impedance, electrochemical,

\section{INTRODUCTION}

Vanadium is the lightest $\mathrm{d}$ - transition metal, compared with other transition metals it has low density, like titanium, and high melting point, like chromium, molybdenum and tungsten. Owing to its low cross-section for nuclear fission, good strength at high temperatures and good thermal conductivity, vanadium can be employed as a construction material in nuclear reactors [1]. At room temperature it is not attacked by air or water and is resistant to most nonoxidizing acids. This, combined with a high resistance to corrosion in hot solutions of mineral acids and fused salts, makes vanadium a promising construction material for chemical equipment [2]. Vanadium is largely used in metallurgical applications and fabrication of batteries. It is used extensively in vanadium-based redox flow batteries [3-6]. Very little electrochemical researches have been devoted to vanadium electrode [7-11]. The corrosion of vanadium in aqueous solutions is studied by using amino acids as corrosion inhibitor [12]. Unlike many transition metals, vanadium shows active behavior $[8,9,13-14]$ and dissolves in acid solutions through a monovalent intermediate. The active behavior of vanadium and its anodic dissolution in aqueous solutions was investigated [15-17], It was found that the rate of metal dissolution is independent of the hydrogen ion concentration or the nature of the present anions. The rate determining step was a monovalent adsorbed intermediate vanadium $\left(\mathrm{V}_{\mathrm{ads}}^{+}\right)$[15].

Inorganic azides are reactive and toxic compounds commonly used as preservatives in biological solutions because of the ability of the $\mathrm{N}_{3}$ functional group to bind tightly to cytochromes and block electron transport and ATP synthesis. Sodium azide is used in the manufacture of the

*Address correspondence to this author at the Chemistry Department, Faculty of Science, Cairo University, Giza 12613, Egypt; Tel: +20 10 1040332; E-mail: Azza_ghoneim@hotmail.com explosive lead azide. It is the principle chemical used to generate nitrogen in automobile safety air bags and airplane escape chutes. It is also used as a biocide in hospitals and laboratories; especially for bulk reagent and stock solutions which may be capable of supporting bacterial growth. $\mathrm{NaN}_{3}$ exerts a biological effect in human platelets, which must be considered when azide-containing reagents are used for studies on platelets function and biological fluids.

Vanadium has only recently been discovered to be necessary for human life, in this respect this study aims to investigate the effect of sodium azide $\left(\mathrm{NaN}_{3}\right)$ concentration and temperature on the electrochemical and corrosion behavior of vanadium using open-circuit potential (OCP), potentiodynamic polarization and electrochemical impedance spectroscopy (EIS) techniques. A comparison between the electrochemical behavior of vanadium metal in azide solutions, and in solutions containing different halides including $\mathrm{F}^{-}, \mathrm{Cl}^{-}, \mathrm{Br}^{-}$or $\mathrm{I}^{-}$ions is also studied. This was intended as azide ion behaves like halide ions in various aspects [18-20].

\section{EXPERIMENTAL METHOD}

The working electrode was made of vanadium rod (99.9\%) from (Nilaco Co., Japan) with a fixed exposed surface area of $0.126 \mathrm{~cm}^{2}$. In each experimental run, the working electrode was mechanically abraded with fine grade of emery papers (600-1200grade). A conventional threeelectrode cell was used with saturated silver/silver chloride reference electrode. The counter electrode was a rectangular platinum sheet in the impedance measurements or a coiled platinum wire in a separate compartment in the polarization experiments. The test electrolytes were prepared using the sodium salts of azide, chloride, bromide, iodide and fluoride ions of analytical grade reagents supplied by BDH using triple distilled water. Open-circuit potential (OCP), potentiodynamic polarization and electrochemical impedance spectroscopy (EIS) measurements were carried 
out using the electrochemical workstation 1M6e Zahnerelectrik GmbH, Meßtechnik, Kronach, Germany provided with Thales software. The dc cathodic and anodic polarization scans were all traced at $1 \mathrm{mVs}^{-1}$ scan rate. For the impedance experiments the excitation ac signal has an amplitude of $10 \mathrm{mV}$ peak to peak in a frequency domain from $0.1 \mathrm{~Hz}$ to $10 \mathrm{kHz}$. The EIS was recorded after reading a steady state open-circuit potential. The experiments were always carried out at $298 \mathrm{~K}$, unless otherwise stated.

\section{RESULTS AND DISCUSSION}

\subsection{Effect of $\mathrm{NaN}_{3}$ Concentration}

\subsubsection{Open-Circuit Potential Measurements}

The open-circuit potential (OCP) of mechanically polished vanadium electrode was recorded over a period of $60 \mathrm{~min}$. in naturally aerated aqueous $\mathrm{NaN}_{3}$ solutions of various concentrations ranging from 0.01 to $2.0 \mathrm{M}$. In all test solutions the electrode potential increases gradually towards more noble values until reaching a steady value $\left(\mathrm{E}_{\mathrm{ss}}\right)$ within $\approx 30 \mathrm{~min}$. The ennobling of OCP indicates healing and further thickening of the native oxide film on the metal surface. The variation of the steady state potentials, $\mathrm{E}_{\mathrm{ss}}$ with the logarithm of the molar concentration of the azide anions can be represented according to [21]:

$\mathrm{E}_{\mathrm{ss}}=\mathrm{a}-\mathrm{b} \log \mathrm{C}_{\mathrm{anion}}$

where $\mathrm{a}$ and $\mathrm{b}$ are constants. Fig. (1) shows the dependence of the rest potential on $\mathrm{NaN}_{3}$ concentration. As can be seen, the final steady-state potential $\left(\mathrm{E}_{\mathrm{ss}}\right)$ value decreases linearly with the increase in azide ion concentration. It is well known that under open circuit conditions, a simultaneous formation and dissolution of the oxide film occurs on the metal surface. The electrical field assisted these processes is assumed to be created from the specific adsorption of the prevailing anion on the metal oxide/electrolyte interface. It has been reported that azide anions exhibit specific adsorption on the dropping mercury electrode (DME) [18, 19] as well as on the solid zirconium electrode [20]. Thus, in lower aerated azide ion concentration, oxygen has higher affinity than azide ion for adsorption on the metal vanadium surface. However, at higher $\mathrm{NaN}_{3}$ concentration the adsorbed azide ions on the oxide surface succeed to partially displace the adsorbed oxygen film, thus $\mathrm{E}_{\mathrm{ss}}$ decreases to some extent.

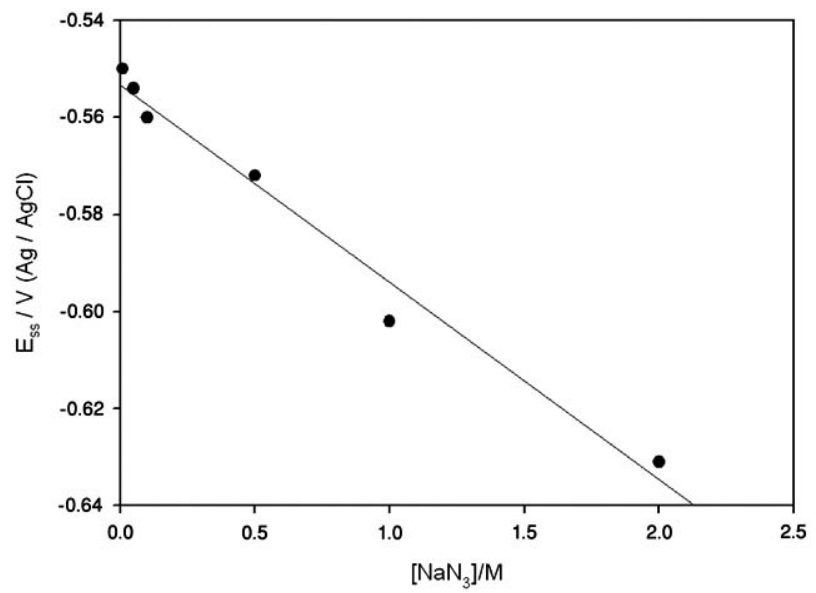

Fig. (1). Variation of Steady-state potential $\left(\mathrm{E}_{\mathrm{ss}}\right)$ vs $\left[\mathrm{NaN}_{3}\right]$ for Vanadium at 298K.
The results reveal that the formation-dissolution process is shifted more towards dissolution as the azide ion concentration is increased, probably due to the increase in the amount of $\mathrm{N}_{3}^{-}$anion adsorption leading to an increase in the aggressive action of the medium.

\subsubsection{Potentiodynamic Polarization Measurements}

Fig. (2) shows the cathodic and anodic potentiodynamic polarization curves for vanadium electrode recorded at scan rate of $1 \mathrm{mVs}^{-1}$ in sodium azide solutions of various concentrations in the range 0.01 to $2.0 \mathrm{M}$ at $298 \mathrm{~K}$. Generally, all scans exhibit similar performance over the potential domain examined versus saturated $\mathrm{Ag} / \mathrm{AgCl}$ electrode. At all $\mathrm{NaN}_{3}$ concentrations the cathodic curves are almost similar in nature, indicating that the same cathodic reaction takes place on the metal. When anodic polarization starts, the current in the active region increases due to metal dissolution. Nevertheless, at more positive potential the rate of variation of the anodic current decreases and the curve merges into a more or less plateau very dependent on the electrolyte concentration. The electrochemical dissolution parameters including the corrosion potential $\left(\mathrm{E}_{\mathrm{corr}}\right)$ and the corrosion current density $\left(i_{\text {corr }}\right)$ were estimated using Thales software for $\mathrm{i} / \mathrm{E}$ analysis $[22,23]$, and are presented in Table 1.

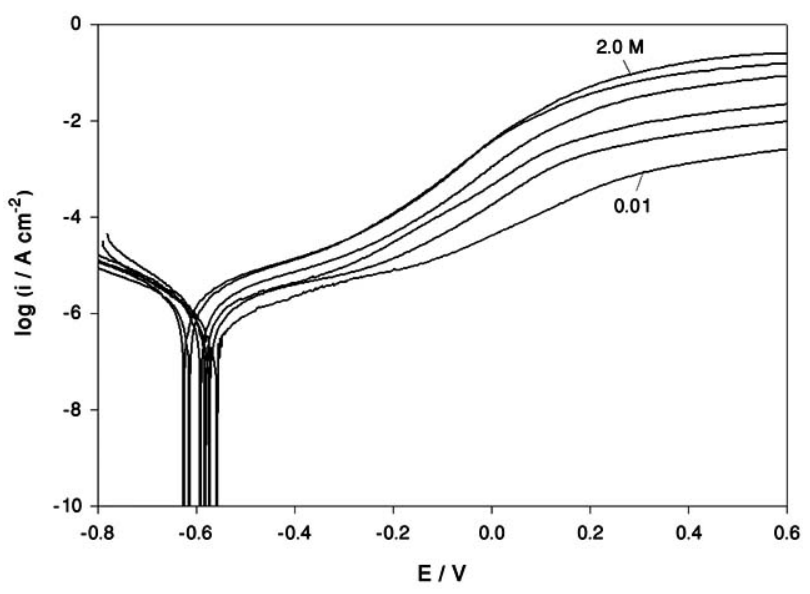

Fig. (2). Potentiodynamic cathodic and anodic polarization scans of vanadium in different concentrations of sodium azide solution at 298K.

The results indicate clearly that $\mathrm{E}_{\text {corr }}$ shifts towards more negative values and the rate of corrosion $i_{\text {corr }}$ increases with increasing the azide ion concentration, which means that vanadium is more susceptible to active anodic dissolution at higher azide ion concentrations. Although vanadium shows active dissolution, has a great tendency towards oxygen and the surface will be covered with a thin film of oxide or mixture of oxides of varying valences. The instability of such oxides explains the corrodability of vanadium surface [17].

\subsubsection{AC Impedance Measurements}

Electrochemical process at metallic electrodes is often affected by the presence of a surface oxide film. Electrochemical impedance spectroscopy (EIS) is a powerful tool in investigating electrochemical and corrosion systems, since it is essentially a steady state technique that capable of 
accessing relaxation phenomena, thus, the corrosion behavior of $\mathrm{V}$ in $\mathrm{NaN}_{3}$ solutions was also confirmed by EIS. The impedance of vanadium was traced after holding the electrode at open circuit for $60 \mathrm{~min}$. in $\mathrm{NaN}_{3}$ solutions of various concentrations in the range from 0.01 to $2.0 \mathrm{M}$. All measurements were carried out in the frequency domain from $10 \mathrm{kHz}$ down to $0.1 \mathrm{~Hz}$. The experimental EIS diagrams are displayed in Fig. (3). as Bode plots, they show that the recorded absolute $|Z|$ tends to become constant at high frequencies, with the phase angle values falling towards zero with increasing frequency. Although the electrochemical impedance was measured down to very low frequencies $(0.1 \mathrm{~Hz})$, the Bode plots do not show second low frequency resistive region (horizontal line and a phase angle $\sim 0^{\circ}$ ) at these frequencies [23]. The plots seem to show two merging phase maxima at medium and low frequency regions commensuration with two overlapping time constant. The phase maxima $\left(\theta_{\max }\right)$ increase and broaden with decreasing azide ions concentration, which reflects the formation of a more protective film on the metal by diluting the solution.

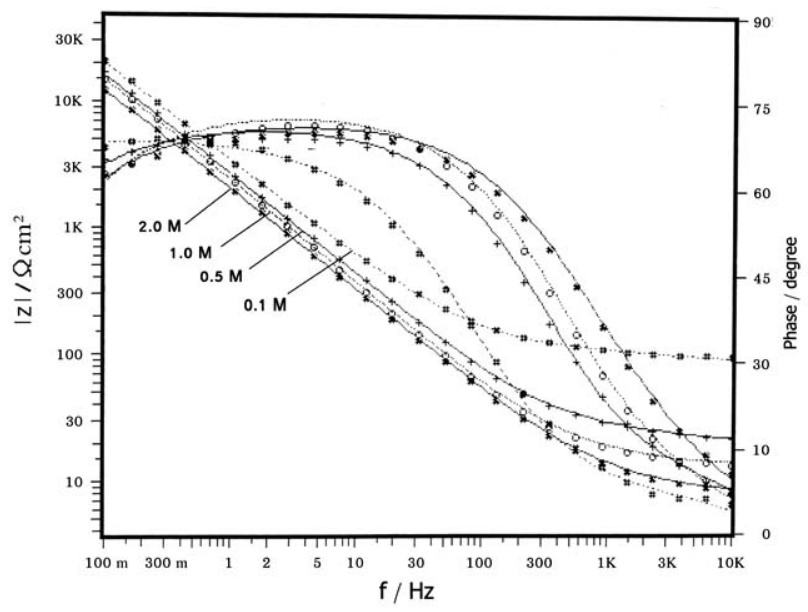

Fig. (3). Bode plots of vanadium in sodium azide solutions of different concentration at $298 \mathrm{~K}$.

The experimental EIS data were analyzed using the equivalent circuit (EC) shown in Fig. (4), which was proposed to simulate the metal/oxide/solution interface, and accounts for the presence of surface oxide film within the interfacial layer [24]. data fitting was done using a complex non-linear least-square (CNLS) fitting procedure in order to establish the suitable EC to fit the experimentally obtained impedance data. The model shown in Fig. (4) consists of a parallel combination of a capacitor $\left(\mathrm{C}_{\mathrm{dl}}\right)$ and a resistor $\left(\mathrm{R}_{\mathrm{ct}}\right)$ in series connection with the solution resistance $\left(R_{s}\right)$, in addition to $\mathrm{R}_{\mathrm{ox}} \mathrm{C}_{\mathrm{ox}}$ combination was introduced to account for the surface oxide film. The time constant at high frequencies is originated from double layer and charge transfer $\left(\mathrm{R}_{\mathrm{ct}}, \mathrm{C}_{\mathrm{dl}}\right)$, while the one at low frequencies is related to the contribution of the oxide film $\left(\mathrm{R}_{\mathrm{ox}} \mathrm{C}_{\mathrm{ox}}\right)$. Instead of pure capacitors, constant phase elements (CPE) were introduced which can be related to a distribution of the relaxation times as a result of different degrees of surface inhomogeneity, roughness effects and variation of surface layers composition [25].

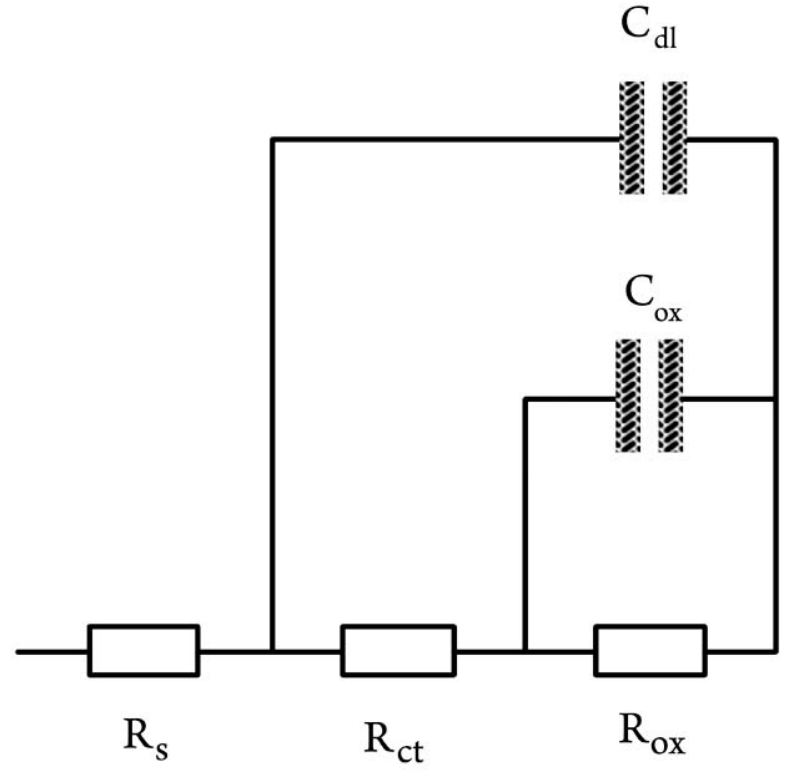

Fig. (4). Equivalent Circuit used to fit the experimental impedance data of vanadium, where: $R_{s}=$ solution resistance, $R_{c t}=$ charge transfer resistance, $\mathrm{R}_{\mathrm{ox}}=$ surface oxide film resistance, $\mathrm{C}_{\mathrm{dl}}=$ double layer capacitance in terms of CPE, $\mathrm{C}_{\mathrm{ox}}=$ oxide film capacitance in terms of CPE.

The impedance associated with the capacitances of the oxide layers is described by the complex frequency dependent impedance $\left(Z_{\mathrm{CPE}}\right)$ defined as [22, 23, 26-28].

$$
Z_{C P E}=\frac{1}{Q(j \omega)^{X}}
$$

where $\mathrm{Q}$ is the frequency-independent real constant of the CPE which is identical to the idealized capacitance $\left(\mathrm{C}_{\mathrm{ox}}\right)$ at $\omega$ $=1$, $\omega$ being the angular frequency $(\omega=2 \pi \mathrm{f})$, $\mathrm{f}$ is the frequency and $\mathrm{j}$ is $\sqrt{-1}$. The value of $\mathrm{x}$ can vary between 1 for a perfect capacitor and -1 for a perfect inductor. The experimental values of $\mathrm{x}$ which are obtained from the fitting procedure ranged between 0.73 and 0.94 . This means that the oxide films formed on vanadium do not behave as perfect capacitors. Also, the results show that the phase angle $\theta_{\max }$ has values less than $90^{\circ}$ which gives more confirmation for the nonideality of the capacitive behavior of the oxide film formed on vanadium.

The calculated equivalent circuit parameters from best fitting of experimental EIS data are listed in Table 1, where $R_{s}$ is the solution resistance, $\left(R_{c t} / C_{d l}\right)$ is the charge transfer resistance and the double layer capacitance. While $\left(\mathrm{R}_{\mathrm{ox}} / \mathrm{C}_{\mathrm{ox}}\right)$ represents the oxide resistance and capacitance respectively. The results in Table $\mathbf{1}$ show that there is a reverse relation between $\left(\mathrm{R}_{\mathrm{ox}}\right)$ and its capacitance $\left(\mathrm{C}_{\mathrm{ox}}\right)$, as well as between $\left(\mathrm{R}_{\mathrm{ct}}\right)$ and its capacitance $\left(\mathrm{C}_{\mathrm{dl}}\right)$. As can be observed from the results the values of $R_{o x}$ are much more greater (in $k \Omega$ ) than for $R_{c t}$ (in $\Omega$ ) which presume the presence of a protective oxide film providing higher corrosion resistance to the sample. and accordingly the EIS data become dominated by the oxide film properties. 
Theoretically, film capacitance is determined by the following formula:

$1 / C=d /\left(\varepsilon_{0} \varepsilon_{\mathrm{r}} A\right)$

where $\varepsilon_{\mathrm{r}}$ is the relative dielectric constant of the oxide film, $\varepsilon_{\mathrm{o}}$ being the permittivity of vacuum $\left(8.85 \times 10^{-12} \mathrm{~F} \mathrm{~cm}^{-1}\right)$ and $\mathrm{A}$ is the electrode area in $\mathrm{cm}^{2}$. Although the actual value of $\varepsilon_{\mathrm{r}}$ within the film is difficult to estimate, a change of $\mathrm{C}$ can be used as an indicator for change in the film thickness (d) [29]. Hence the reciprocal capacitance $(1 / \mathrm{C})$ is directly proportional to oxide film thickness [30, 31].

From Table 1. It is clear that the values of $\left(1 / \mathrm{C}_{\mathrm{ox}}\right)$ as well as its resistive component $R_{o x}$ were found to decrease with increasing the azide ion concentration. These results can be attributed to the dissolution and thinning of the oxide film as the aggressiveness of the solution increases, in good agreement with the dc and polarization measurements.

\subsection{Effect of Temperature on the Corrosion Behavior of Vanadium}

\subsubsection{Potentiodynamic Measurements}

To study the effect of temperature, the electrochemical corrosion behavior was investigated potentiodynamically in naturally aerated $0.5 \mathrm{M} \mathrm{NaN}$ solution as a function of temperature in the range $288-328 \mathrm{~K}$. The general trend is an increase in the rate of corrosion ( $i_{\text {corr }}$ ) with increasing temperature. A plot of $\log \mathrm{i}_{\text {corr }}$ versus $1 / \mathrm{T}$ obeys the familiar Arrhenius equation [32];

$\log \mathrm{i}_{\text {corr }}=-\frac{E a}{2.303 R T}+$ constant

A straight line of Arrhenius plot was obtained and presented in Fig. (5). The activation energy $E_{a}$ is equal to $23.6 \mathrm{~kJ} / \mathrm{mol}$. This value is less than $40 \mathrm{~kJ} / \mathrm{mol}$, which supports the view that the dissolution of the metal is one electron charge transfer process $[9,33]$. This supports the mechanism suggested by Armstrong and Henderson [15], and presented by the following;

$$
\begin{aligned}
& \mathrm{V}_{(\mathrm{s})} \stackrel{\text { Slow }}{\longrightarrow} \mathrm{V}(\mathrm{I})+\mathrm{e}^{-} \\
& \mathrm{H}_{2} \mathrm{O}+\mathrm{V}(\mathrm{I})_{\mathrm{ads}} \underset{\text { Fast }}{\longrightarrow} \mathrm{VO}^{+2}+2 \mathrm{H}^{+}+3 \mathrm{e}^{-}
\end{aligned}
$$

The results give more evidence that vanadium has higher susceptibility to corrosion in $\mathrm{NaN}_{3}$ medium as its corrosion process is associated with a lower effective activation barrier indicated by its lower $\mathrm{E}_{\mathrm{a}}$ value.

\subsubsection{Impedance Measurements}

The effect of temperature was also investigated by EIS. Fig. (6) shows the fitted frequency response diagrams of $\mathrm{V}$ in $0.5 \mathrm{M} \mathrm{NaN}$ solution at different temperatures in the domain from 288 to $328 \mathrm{~K}$. The experimental EIS data were analyzed using the same equivalent circuit shown in Fig. (4). Plotting the values of the oxide film thickness $\left(1 / \mathrm{C}_{\mathrm{ox}}\right)$ and also its corresponding $R_{o x}$ values, both against the absolute temperature (K) are shown in Fig. (7a, b). The plots show a pronounced decrease of the two parameters with raising the ambient temperature, probably due to increasing solubility of the oxide film in $0.5 \mathrm{M} \mathrm{NaN}$ solution in concordance with the polarization results.

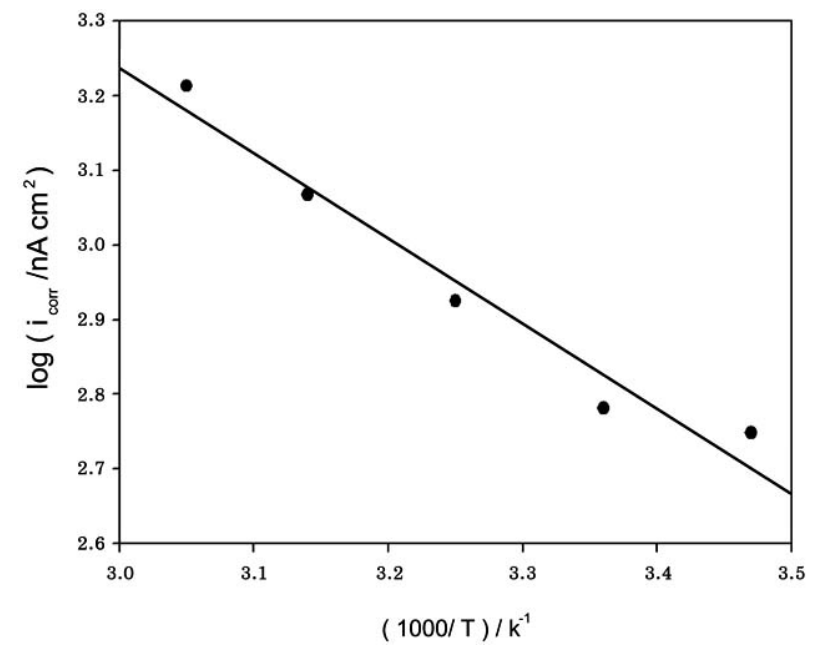

Fig. (5). Arrhenius plot for the effect of temperature on the corrosion current density of vanadium in $0.5 \mathrm{M} \mathrm{NaN}_{3}$ solutions.

\subsection{Effect of Anion Nature}

\subsubsection{Potentiodynamic Measurements}

Fig. (8) shows the potentiodynamic polarization curves for $\mathrm{V}$ in $0.5 \mathrm{M} \mathrm{N}_{3}^{-}$salt solution in comparison to the other $0.5 \mathrm{M}$ salt solutions of the different deleterious halide anions, namely $\mathrm{F}^{-}, \mathrm{Cl}^{-}, \mathrm{Br}^{-}$and $\mathrm{I}^{-}$at $298 \mathrm{~K}$. Generally all scans show similar performance, however for $\mathrm{Br}^{-}$and $\mathrm{Cl}^{-}$solutions there was a small detectable current plateau appears after the corrosion potential for the anodic curves, this indicates the

Table 1. Electrochemical Corrosion and Equivalent Circuit Parameters of V in Different Concentrations of Sodium Azide

\begin{tabular}{|c|c|c|c|c|c|c|c|}
\hline $\begin{array}{c}{\left[\mathbf{N a N}_{3}\right] /} \\
\mathbf{M}\end{array}$ & $\begin{array}{c}\mathbf{E}_{\text {corr }} / \\
\mathbf{m V}\end{array}$ & $\begin{array}{c}\mathbf{i}_{\text {corr }} / \\
\mathbf{n A c m}^{-2}\end{array}$ & $\begin{array}{c}\mathbf{R}_{\mathbf{0 x}} / \\
\mathbf{k} \boldsymbol{\mathbf { c }} \mathbf{c m}^{2}\end{array}$ & $\begin{array}{c}\mathrm{C}_{\text {ox }} / \\
\mu \mathrm{Fcm}^{-2}\end{array}$ & $\begin{array}{c}\mathbf{R}_{\mathrm{ct}} / \\
\mathbf{\Omega} \mathbf{c m}^{2}\end{array}$ & $\begin{array}{c}\mathrm{C}_{\mathrm{dl}} / \\
\mu \mathrm{Fcm}^{-2}\end{array}$ & $\begin{array}{c}\mathbf{R}_{\mathbf{s}} / \\
\mathbf{\Omega}\end{array}$ \\
\hline 0.01 & -558.8 & 236.5 & 199.5 & 19.7 & 25.6 & 4.72 & 725.1 \\
\hline 0.05 & -574.0 & 242.0 & 159.2 & 31.6 & 13.4 & 13.2 & 199.9 \\
\hline 0.1 & -581.5 & 334.9 & 44.8 & 69.3 & 3.9 & 18.5 & 86.6 \\
\hline 0.5 & -591.0 & 603.9 & 16.1 & 74.9 & 2.3 & 31.5 & 20.8 \\
\hline 1.0 & -614.3 & 631.7 & 9.3 & 87.7 & 2.2 & 37.9 & 13.3 \\
\hline 2.0 & -624.0 & 739.7 & 8.2 & 108.8 & 1.4 & 43.7 & 6.8 \\
\hline
\end{tabular}
Solutions at $298 \mathrm{~K}$ 
existence of a partially protective surface film. The corrosion parameters listed in Table 2 reveal that the values of $i_{\text {corr }}$ and the extent of film dissolution are stimulated in the following order: $\mathrm{F}^{-}>\mathrm{N}_{3}^{-}>\mathrm{I}^{-}>\mathrm{Cl}^{-}>\mathrm{Br}^{-}$.

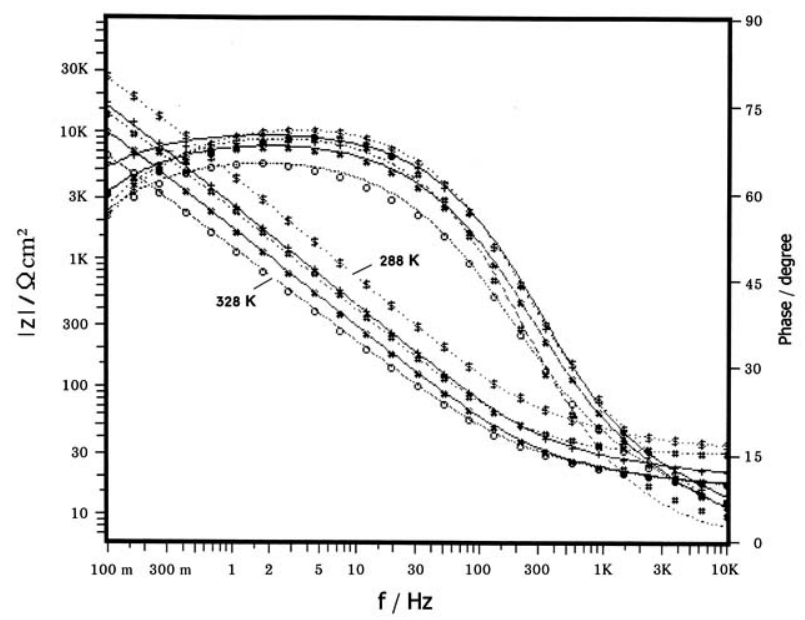

Fig. (6). Bode plots for vanadium in $0.5 \mathrm{M} \mathrm{NaN}$ solutions at different temperatures.

\subsubsection{Impedance Measurements}

EIS was also conducted after $60 \mathrm{~min}$. immersion time in $0.5 \mathrm{M}$ salt solutions of the prevailing anions in order to measure the resistance and capacitance of the system as a function of the identity of the halogen ion compared to $\mathrm{N}_{3}^{-}$ ion. The impedance spectra as Bode diagrams after the fitting procedure using the EC shown in Fig. (4) are shown in Fig. (9), the fitted parameters in Table 2 reveal that $R_{o x}$ and $1 / C_{o x}$ values for the film grown spontaneously in those solutions decrease in the order: $\mathrm{Br}^{-}>\mathrm{Cl}^{-}>\mathrm{I}^{-}>\mathrm{N}_{3}{ }^{-}>\mathrm{F}^{-}$. This important feature obviously indicates that vanadium has tendency to form thicker oxide film in the above sequence.

The results reflect a difference in the reactivity of these anions towards catalyzing the spontaneous growth of the oxide layers on vanadium via a dissolution-formation mechanism. This difference could be related to a chemical interaction between the vanadium oxide and the halogen or the azide ion, which occurs through the adsorption of these species on the surface of the oxide covered metal, where they induce electric field necessary for ion transport through the film [34].
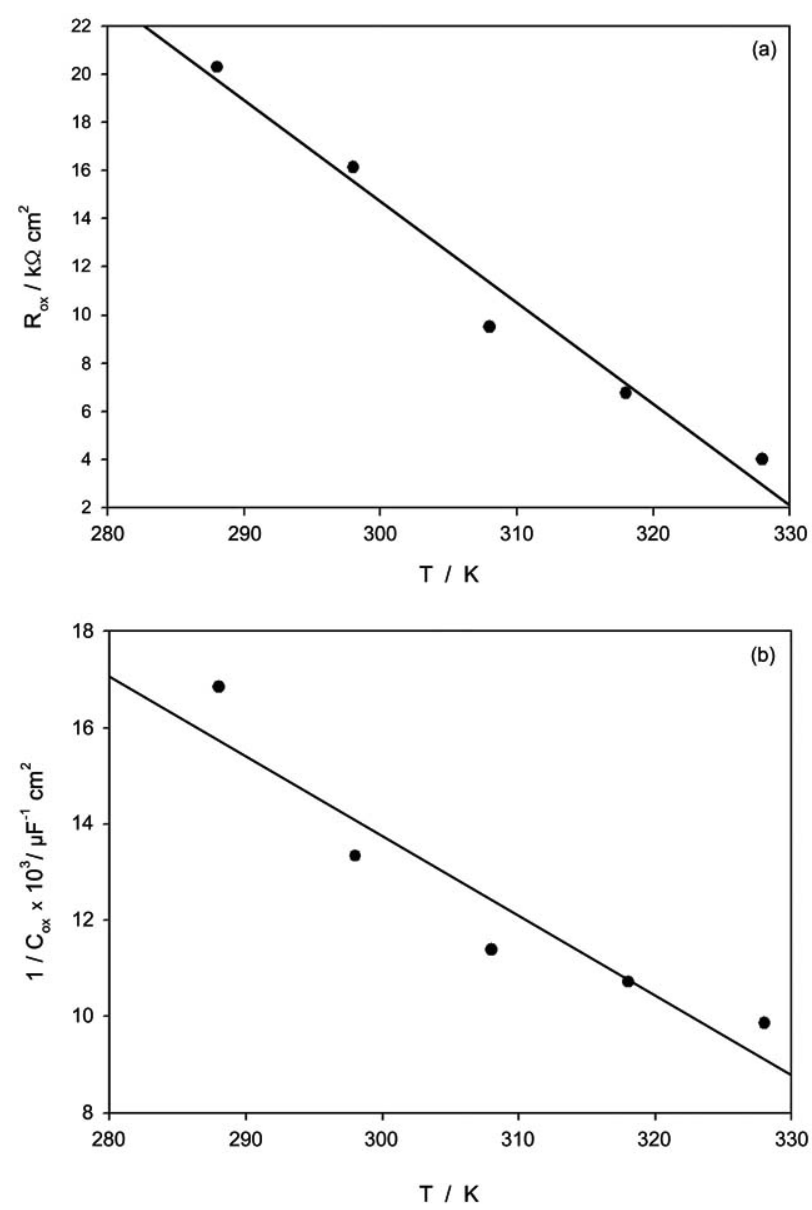

Fig. (7). (a) resistance $\left(\mathrm{R}_{\mathrm{ox}}\right)$ and (b) relative thickness $\left(1 / \mathrm{C}_{\mathrm{ox}}\right)$ of spontaneously formed oxide film on vanadium in $0.5 \mathrm{M} \mathrm{NaN}_{3}$.

The results in Table 2 reveals that $R_{o x}$ values are in the range of $\mathrm{k} \Omega \mathrm{cm}^{2}$ in all media investigated, with its maximum value in bromide solution, on the other hand, the capacitance component of the oxide film $\left(\mathrm{C}_{\mathrm{ox}}\right)$ follows a reverse trend. The results show a lower resistance $\left(\mathrm{R}_{0 \mathrm{x}}\right)$ and thickness $\left(1 / C_{\text {ox }}\right)$ of the oxide layer in fluoride solution. This seems to be related to the lower adsorbability of this ion which would induce a smaller field across the oxide leading to a reduced rate of film thickening.

Table 2. Electrochemical Corrosion and Equivalent Circuit Parameters of V in 0.5M Sodium Salt Solutions of Different Anions at 298K

\begin{tabular}{|c|c|c|c|c|c|c|c|}
\hline Anions & $\begin{array}{c}\mathbf{E}_{\text {corr }} / \\
\mathbf{m V}\end{array}$ & $\begin{array}{c}\mathbf{i}_{\text {corr }} / \\
\text { nAcm }^{-2}\end{array}$ & $\begin{array}{c}\mathbf{R}_{\mathrm{ox}} / \\
\mathbf{k} \Omega \mathbf{c m}^{2}\end{array}$ & $\begin{array}{c}\mathrm{C}_{\mathrm{ox}} / \\
\mu \mathrm{Fem}^{-2}\end{array}$ & $\begin{array}{c}\mathbf{R}_{\mathrm{ct}} / \\
\mathbf{\Omega} \mathrm{cm}^{2}\end{array}$ & $\begin{array}{c}\mathrm{C}_{\mathrm{dl}} / \\
\mu \mathrm{Fem}^{-2}\end{array}$ & $\begin{array}{c}\mathbf{R}_{\mathrm{s}} / \\
\mathbf{\Omega}\end{array}$ \\
\hline $\mathrm{Br}^{-}$ & -557.3 & 252.3 & 35.9 & 38.6 & 8.8 & 21.1 & 10.7 \\
\hline $\mathrm{Cl}^{-}$ & -567.2 & 265.1 & 21.4 & 46.0 & 3.7 & 25.0 & 19.0 \\
\hline $\mathrm{I}^{-}$ & -590.0 & 288.8 & 16.9 & 47.6 & 2.0 & 29.0 & 15.9 \\
\hline $\mathrm{N}_{3}^{-}$ & -591.0 & 603.9 & 16.1 & 74.9 & 2.3 & 31.5 & 20.8 \\
\hline $\mathrm{F}^{-}$ & -595.1 & 920.6 & 6.5 & 90.2 & 1.5 & 47.1 & 17.1 \\
\hline
\end{tabular}


On the other hand, in this aggressive medium the dissolution product, being likely the stable hydrated tetrafluoride salt, may remain in the interface region hindering further direct access of more $\mathrm{F}^{-}$ion to the surface, thereby decreasing the field strength that causing the ionic migration [35]. Similar behavior was previously reported for zirconium in fluoride medium [36].

However, in iodide medium the values of $\mathrm{R}_{\mathrm{ox}}$ and $1 / \mathrm{C}_{\mathrm{ox}}$ are lower than those in chloride and bromide medium. In spite of its high specific adsorption, the high surface concentration of $\mathrm{I}^{-}$ would cause blockage of the surface via the formation of some species which partially inhibit the oxide growth process. This is consistent with the previously reported results for zirconium in KI solution $[37,38]$. The results indicate also that in the three other halide media, the reactivity towards oxide growth process proceeds parallel to the rank of their ionic radii and that $\mathrm{Br}^{-}$is the most effective solution towards partially protective film formation.

For the azide anion, it is assumed to exhibit specific anion adsorption [18] and the amount of specifically adsorbed charge depends on the azide solution concentration.

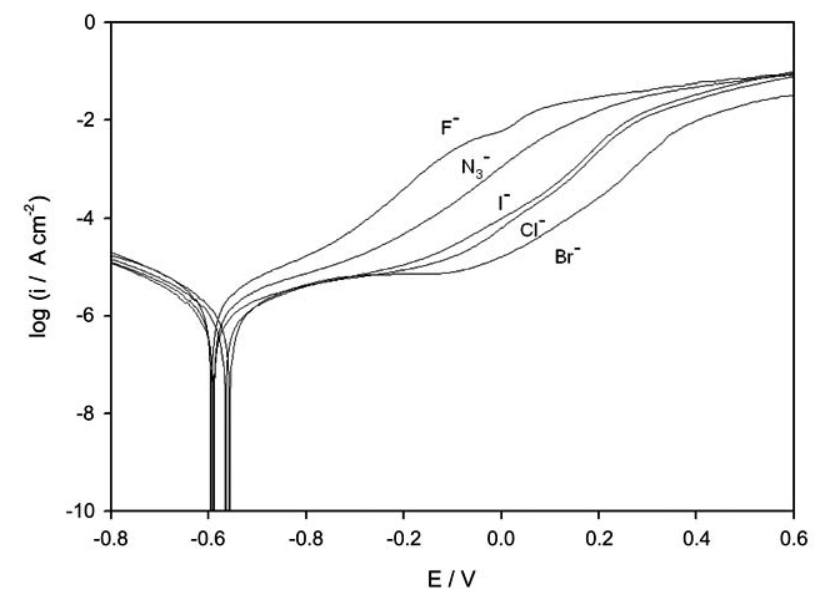

Fig. (8). potentiodynamic cathodic and anodic polarization scans of vanadium in $0.5 \mathrm{M}$ solutions of different anions $\left(\mathrm{F}^{-}, \mathrm{N} 3{ }^{-}, \mathrm{I}^{-}, \mathrm{Cl}^{-}\right.$and $\left.\mathrm{Br}^{-}\right)$; at $298 \mathrm{~K}$.

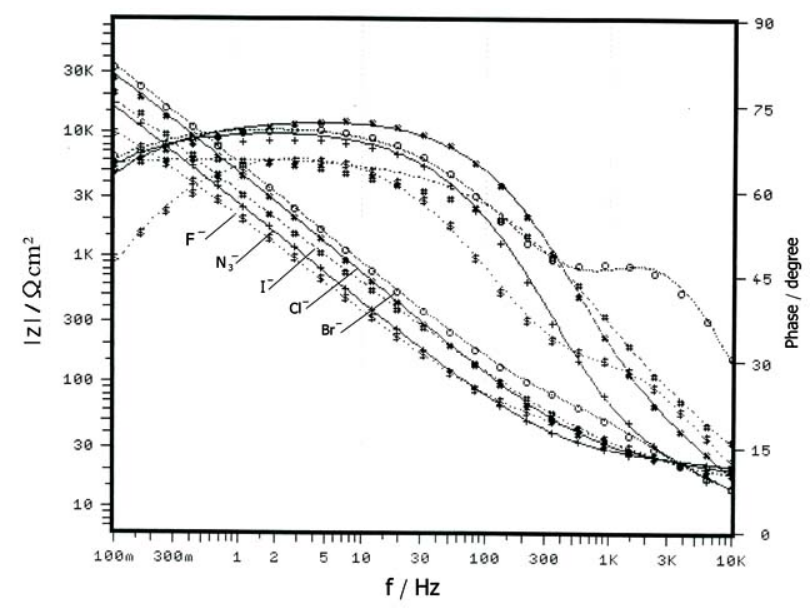

Fig. (9). Bode plots for vanadium in $0.5 \mathrm{M} \mathrm{NaN}$ solutions of different anions $\left(\mathrm{F}^{-}, \mathrm{N}^{-}, \mathrm{I}^{-}, \mathrm{Cl}^{-}\right.$and $\left.\mathrm{Br}^{-}\right)$; at $298 \mathrm{~K}$.

\section{CONCLUSIONS}

1- The open-circuit potential measurements for vanadium electrode in $\mathrm{NaN}_{3}$ solutions of different concentrations showed a shift in $\mathrm{E}_{\mathrm{ss}}$ towards more negative values as the azide concentration is increased, probably due to the increase in the adsorbed amount of $\mathrm{N}_{3}{ }^{-}$anion leading to an increase in the aggressive action of the medium.

2- The rate of corrosion $i_{\text {corr }}$ of vanadium increases with increasing either azide ion concentration or temperature. $R_{o x}$ and $1 / C_{o x}$ values of the surface film, which are obtained from impedance measurements, confirmed well these results.

3- The behavior of vanadium in the azide medium is also compared with that in other halide salt solutions. It was found that higher tendency for spontaneous film growth can be achieved in the sequence; $\mathrm{Br}^{-}>$ $\mathrm{Cl}^{-}>\mathrm{I}^{-}>\mathrm{N}_{3}^{-}>\mathrm{F}^{-}$.

\section{REFERENCES}

[1] Tomlinson, W. J.; Rushton, R.; Cindery, R.; Palmmer, S. Anodic polarization and corrosion of vanadium, and $\mathrm{V}---\mathrm{Ta}, \mathrm{V}---\mathrm{W}, \mathrm{V}---\mathrm{Cr}$ and V---Cr---W alloys in $10 \% \mathrm{H}_{2} \mathrm{SO}_{4}$ and $3 \% \mathrm{NaCl}$ in water. J. Less Common Met., 1987, 132, L1-L4.

[2] Kinzel, A. Vanadium metal-a new article of commerce. Met. Prog., 1950, 58, 315-321.

[3] Rychcik, M.; Skyllas-Kazacos, M. Evaluation of electrode materials for vanadium redox cell. J. Power Sources, 1987, 19, 45-54.

[4] Kazacas, M.; Skyllas-Kazacos, M. Performance characteristics of carbon plastic electrodes in the all-vanadium redox cell. J. Electrochem. Soc., 1989, 136, 2759-2760.

[5] Skyllas-Kazacos, M. Novel vanadium chloride / polyhalide redox flow battery. J. Power Sources, 2003, 124, 299-302.

[6] Rahman, F.; Skyllas-Kazacos, M. Vanadium redox battery: positive half cell electrolyte studies. J. Power Sources, 2009, 189, 1212-19.

[7] Ameer, M. Electrochemical behavior of vanadium in EDTA. Mat. Wiss. U. Werkstofftech, 2003, 34, 583-586.

[8] Ameer, M. Impedance behavior of anodic dissolution of vanadium in sulphuric acid. Mat. Wiss. U. Werkstofftech, 1997, 28, 529-533.

[9] Ameer, M. Electrochemical performance of vanadium in sodium chloride solution. Mater. Corrosion, 2000, 51, 242-246.

[10] Privman, M.; Hepel, T. Electrochemistry of vanadium electrodes part 1. cyclic voltammetry in aqueous solutions. J. Electroanal. Chem., 1995, 382, 137-144.

[11] Alonzo, V.; Darchen A.; Le Fur, E.; Pivan, J.Y. Electrochemical behavior of a vanadium anode in phosphoric acid and phosphate solutions. Electrochim. Acta, 2006, 51, 1990-1995.

[12] El Rabiee, M. M.; Helal N. H.; Abd El-Hafez, G. H. M.; Badawy, W. A. Corrosion control of vanadium in aqueous solutions by amino acids. J. Alloys Comp., 2008, 459, 466-471.

[13] Ameer, M.A.; Ghoneim, A.A. Electrochemical oxidation of vanadium as studied by electron spin resonance spectroscopy. Electrochem. Soc., $\mathbf{1 9 9 5}, 142,4082-4084$.

[14] Hornkjol, S. Passive behavior of hafnium. Electrochim. Acta, 1988, 33, 337-430.

[15] Armstrong, R.D.; Henderson, M. The anodic dissolution of vanadium in acid solutions. J. Electroanal. Chem., 1980, 26, 381-386.

[16] Hornkjol, S.; Hornkjol, I.M. Anodic behavior of vanadium in acidic solutions. Electrochim. Acta, 1991, 36, 577-80.

[17] Al-kharafi, F.M.; Badawy, W. A. Electrochemical behavior of vanadium in aqueous solutions of different $\mathrm{pH}$. Electrochim. Acta, 1997, 42, 579-586.

[18] Moussa, A. A.; Abou Romia, M. M. Electrochemistry of the azide ion II. Differential capacitance of mercury in aqueous sodium azide solutions; specific adsorption of azide ion compared with that of halide ions. Electrochim. Acta, 1970, 15, 1381-1390.

[19] Moussa, A.A.; El-Taib Heakal, F. Medium effects on the electroreduction of In(III) at DME: formation of electrocapillary active 
In(III) species in aqueous media of different anions. J. Electroanal. Chem., 1980, 115, 247-251.

[20] Ghoneim, A.A. corrosion behavior of zirconium electrode in sodium azide electrolyte as compared to the alkali halide solutions. Mater. Corrosion, 2004, 55, 617-622.

[21] Abd El Kader, J.M.; Shams El Din, A.M. Film thickening on nickel in aqueous solution in relation to anion type and concentration. $\mathrm{Br}$. Corros. J., 1979, 14, 40-45

[22] El-Taib Heakal, F.; Fekry, A.M.; Ghoneim, A.A. Corrosion characterization of new tin-silver binary alloys in nitric acid solutions. Corrosion Sci., 2008, 50, 1618-1626.

[23] Fekry, A.M. The influence of chloride and sulphate ions on the corrosion behavior of $\mathrm{Ti}$ and $\mathrm{Ti}-6 \mathrm{Al}-4 \mathrm{~V}$ alloy in oxalic acid. Electrochim. Acta, 2009, 54, 3480-3489.

[24] Ismail, K.M.; Fathi, A.M.; Badawy, W.A. the influence of Ni content on the stability of copper-nickel alloys in alkaline sulphate. J. Appl. Electrochem., 2004, 34, 823-831.

[25] Fonseca, C.; Barbosa, M.A. Corrosion behaviour of titanium in biofluids containing $\mathrm{H}_{2} \mathrm{O}_{2}$ studied by electrochemical impedance spectroscopy. Corrosion Sci., 2001, 43, 547-559.

[26] Machdonald, J.R. Impedance Spectroscopy Emphasizing Solid Materials and Systems, John Wily \& Sons: New York, 1987.

[27] El-Taib Heakal, F.; Ghoneim, A.A.; Fekry, A.M. stability of spontaneous passive films on high strength Mo- containing stainless steels in aqueous solutions. J. Appl. Electrochem., 2007, 37, 405-413.

[28] Juttner, K. Electrochemical impedance spectroscopy (EIS) of corrosion processes on inhomogeneous surfaces. Electrochim. Acta, 1990, 35, 1501-1508.
[29] El-Taib Heakal, F.; Ameer, M.A.; El-Aziz, A.; Fekry, A.M. Electrochemical behaviour of Mo-containing austenitic stainless steels in buffer solution. Mat. Wiss. U. Werkstofftech, 2004, 35, 407-412.

[30] Leach, J.S.; Pearson, B. R. The effect of foreign ions upon the electrical characteristics of anodic $\mathrm{ZrO}_{2}$ films. Electrochim. Acta, 1984, 29, 12711282.

[31] El-Taib Heakal, F.; Mogoda, A.S.; Mazhar, A.A.; El-Basiouny, M. S. Kinetic studies on the dissolution of the anodic oxide film on titanium in phosphoric acid solutions. Corrosion Sci., 1987, 27, 453-462.

[32] Atkins, P.W. Physical Chemistry, $6^{\text {th }}$ ed.; Oxford University Press: U.K., 1998, p. 864.

[33] Wright, G.A. Discussion of "Studies of the electrochemical kinetics of indium, III. Systems In $+\mathrm{InCl}_{3}$ and In + combined sulphate-chloride electrolyte". J. Electrochem. Soc., 1967, 114, 1263.

[34] Abd El-Kader, J.M.; Abd El-Wahab, F.M.; El-shayeb, H.A.; Khedr, M.G.A. Oxide film thickening on $\mathrm{Ti}$ in aqueous solution in relation to anion type and concentration. Br. Corrosion J., 1981, 16, 111-116.

[35] Abd El-Rahman, H. A.; Abou Romia, M. M. Anodization of hafnium in phosphoric acid solutions. J. Appl. Electrochem., 1990, 20, 39-44.

[36] El-Taib Heakal, F.; Mogoda, A.S.; Mazhar, A.A.; Ghoneim, A.A. Effect of fluoride media on the stability of anodic $\mathrm{ZrO}_{2}$ films. Corrosion, 1990, 46, 247-253.

[37] Gardiazabal, I.; Cordova, R.; Gomez, H.; Shrebler, R. The electrochemical behavior of zircaloy-4 electrodes in acid iodide solution. J. Electroanal. Chem., 1988, 240, 299-308.

[38] Ghoneim, A.A.; Saleh, H.M.; El-Taib Heakal, F. On the role of iodine in the oxidation of $\mathrm{Zr}$ in KI medium. Monatsheft Für Chemie, 1998, $129,799-810$.

(C) A.A. Ghoneim; Licensee Bentham Open.

This is an open access article licensed under the terms of the Creative Commons Attribution Non-Commercial License (http: //creativecommons.org/licenses/by$\mathrm{nc} / 3.0 /$ ) which permits unrestricted, non-commercial use, distribution and reproduction in any medium, provided the work is properly cited. 